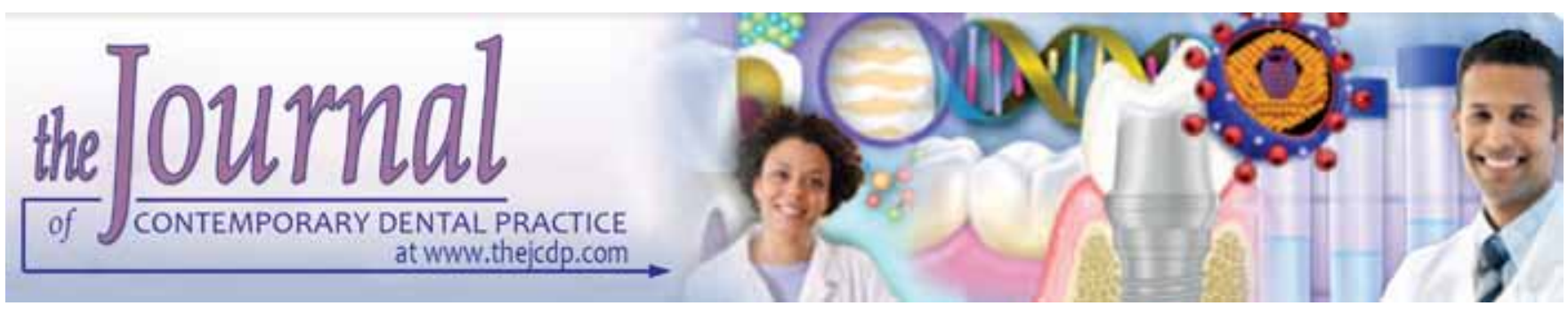

\title{
MM-MTA for Direct Pulp Capping: A Histologic Comparison with ProRoot MTA in Rat Molars
}

\author{
Issam Tanios Khalil, Tony Sarkis, Alfred Naaman
}

\section{ABSTRACT}

Aim: To compare the histomorphological response of rat dental pulps capped with MM-MTA and ProRoot MTA at 1, 2 and 4 weeks postoperatively.

Materials and methods: Direct pulp capping with MM-MTA and ProRoot MTA, overlaid with light-cured composite resin, was performed on right and left maxillary first molars of 20 Wistar rats. Animals were killed at 1, 2 and 4 weeks postoperatively. Biopsy samples were stained and viewed by light microscopy to determine dentin bridge formation. Data were statistically evaluated with the Kruskal-Wallis test $(p<0.05)$.

Results: Absence of dentin bridge formation at 1 week, partial dentin bridge formation at 2 weeks and complete dentin bridge formation at 4 weeks are observed with MM-MTA and ProRoot MTA. The results showed no statistically significant difference between both materials at 4 weeks.

Conclusion: Both materials produced similar responses in the pulp when used for pulp capping in intact, caries-free molars of rats.

Keywords: Direct pulp capping, MM-MTA, ProRoot MTA, Rats molars.

How to cite this article: Khalil IT, Sarkis T, Naaman A. MM-MTA for Direct Pulp Capping: A Histologic Comparison with ProRoot MTA in Rat Molars. J Contemp Dent Pract 2013;14(6):10191023.

\section{Source of support: Nil}

Conflict of interest: None declared

\section{INTRODUCTION}

Direct pulp capping is a dental procedure in which the exposed pulp is covered with a suitable protection material to minimize additional injury and to allow exposed tissue to heal through a protective response of reparative dentinogenesis resulting in dentin bridge formation. ${ }^{1}$ Mineral trioxide aggregate (MTA: commercially available as ProRoot MRA: Dentsply, Tulsa, OK, USA) that was initially used for endodontics to seal off all pathways of communication between the root canal system and the internal tissues was suggested also as a suitable material to be used in vital pulp therapies. ${ }^{2}$ Several laboratory and in vivo studies have reported that MTA has characteristics, such as biocompatibility, marginal adaptation, high $\mathrm{PH}$, high calcium ion release and low solubility ${ }^{3,4}$ and that MTA exhibits better results than other pulp capping agents when used as direct pulp capping on uninflamed, traumatically exposed pulps. ${ }^{5,6}$

But one of the reported drawbacks to MTA is the difficulty in handling and placement (sandy consistency), as well as its slow setting time which often necessitates another treatment appointment for the final restoration. ${ }^{7-9}$ Many researchers worked on developing new classes of MTA to overcome its negative characteristics. ${ }^{8,10}$ In this context, MM MTA, a new endodontic cement for MicroMega (5-12, rue du Tunnel F-25006 Besançon Cedex-France). MMMTA like ProRoot MTA is mainly composed of Portland cement with a variation in the amount of gypsum, in the radiopaque component (for purposes of dental diagnostics) and the addition of calcium carbonate $\left(\mathrm{CaCO}_{3}\right)$ (for enhanced viscosity and putty consistency). According to the manufacturers, MM-MTA presents three main advantages over MTA:

- MM-MTA accelerated setting time allows to finish final restoration within a single appointment time frame (20 minutes) instead of postponing it.

- MM-MTA putty consistency offers an ability to manipulate and rinse around it without the possibility of displacement of the cement when it is condensed in the cavity.

- MM-MTA presentation in predosed capsules and mechanical trituration allows clinicians to get a stable composition and fluidity instead of hand mixing powder and liquid. And depending on the application site, the cement can be directly delivered in the desired location through the nozzle of the capsule. 
The purpose of the present study was to evaluate and compare the histomorphological features of MM-MTA and ProRoot MTA after pulp capping on rats molars.

\section{MATERIALS AND METHODS}

All animal experiments were conducted by an authorized person in compliance with the European directive (86/609 of the 24th of November 1986) in the Surgical Research Laboratory at the Faculty of Medicine of Saint-Joseph University, Beirut-Lebanon. Forty caries-free, maxillary right and left first molars of 20 Wistar rats aged 6 to 7 weeks (weight about $150 \mathrm{gm}$ each) were used for these investigations. General anesthesia was obtained with intramuscular injection of an association of Ketamine (Ketalar, Warner, Lambert, Ireland) $(65 \mathrm{mg} / \mathrm{Kg}$ body weight) and Xylasine (Rompun, Bayer, Leverkusen, Germany) ( $7 \mathrm{mg} / \mathrm{Kg}$ body weight). Teeth were disinfected with $0.2 \%$ chlorhexidine gluconate. Two teeth per rat were prepared. Class I occlusal cavities were prepared on the occlusal surface to approximately half the distance through dentin. Low speed tapered round diamond burs (Intensive, Switzerland) (0.84 $\mathrm{mm}$ in diameter) were cooled with copious sterile water to flush the drilling bur adequately. The pulp was perforated by pressing the tip of a steel $(0.36 \mathrm{~mm}$ in tip diameter) through the remaining thickness of dentin.

Bleeding was weak and stopped after a few seconds. The cavities were rinsed with physiological serum and gently dried with a cotton pellet before being capped. MMMTA was placed on the exposed pulp of 18 molars with an MTA-gun (right molar), and ProRoot MTA mixed with distilled water according to the manufacturer's instructions and placed on 18 left molars with an amalgam-carrier and condensed with a sterile paper point (left molar). All cavities were then filled with dentin adhesive and composite. As a control group, the pulp-capping procedure was performed in the absence of MTA on maxillary first molar on two animals, i.e. the composite resin was placed directly in contact with the pulp. Following the surgical procedure, one animal did not recover from the anesthesia and died 4 hours after treatment. The 19 surviving mice recovered within 6 to 10 hours, and were then housed individually, with food and water ad libitum. Paracetamol $[(0.06 \mathrm{mg}) 1$ day $] 1$ was delivered in water for 72 hours for analgesia.

Treated animals were killed by perfusion through the heart with the fixative solution ( $10 \%$ neutral formalin) at increasing time periods following the clinical procedures as shown in Table 1.

Maxillary segments were carefully block dissected and fixed by immersion in $10 \%$ NBF for an additional 24 hours. After decalcification in buffered EDTA, tissues were processed routinely for paraffin embedding. Serial sections were then prepared in the para-sagittal plane and mounted on silane-coated slides; representative sections from a total of 38 treated first molars were stained with hematoxylin and eosin (H\&E) and then were evaluated by light microscopy.

\section{Light Microscopy Observations}

Histological examination confirmed the successful completion of the procedure, the localization of the cavity and the diameter of the pulp exposure at around $160 \mu \mathrm{m}$.

At 1 week postoperatively, no dentin bridge formation was observed with both materials.

At 2 weeks postoperatively, the first signs of the healing process were observed, a partial bridge was visible with presence of little communication of both capping material with dental pulp (Fig. 1).

At 4 weeks postoperatively, a complete dentin bridge was visible (Fig. 2) except for one specimen capped with MM-MTA and two with ProRoot MTA where the bridge formation was still incomplete.

In the negative control in which no MTA was used for pulp capping, the histology of the pulp appeared normal, but neither dentin bridge nor any signs of healing of the exposure were evident, up to 4 weeks after treatment.

\section{Statistical Results}

The statistical analysis was performed using a software program (SPSS for windows version 17.0, Chicago, IL, USA). The alpha error was set at 0.05 . The outcome variable of the study was the formation of dentin bridge (absent, partial or complete). This variable was compared among teeth treated with MM-MTA and ProRoot MTA at 1, 2 and 4 weeks (Tables 2 and 3). The tooth was defined as the statistical units. The Fisher Exact tests were used. At 1 week, there was no mineralization among teeth treated with MM-MTA and those treated with ProRoot MTA. However at 2 weeks, $3(75 \%)$ teeth treated with MM-MTA presented partial dentin bridge formation and $4(100 \%)$ treated with ProRoot MTA. Comparison at 4 weeks between teeth treated with MM-MTA and ProRoot MTA was also conducted. Eight $(88.9 \%)$ teeth treated with MM-MTA and 7(77.8\%) teeth treated with ProRoot MTA presented a complete dentin bridge formation. The difference was not significant $(\mathrm{p}$-value $=1.000)($ Table 4$)$.

\section{DISCUSSION}

If the main indicator of success in direct pulp capping or pulpotomies is the formation of complete or partial dentin bridge with none or little communication between material and dental pulp, it can be concluded that all specimens in 


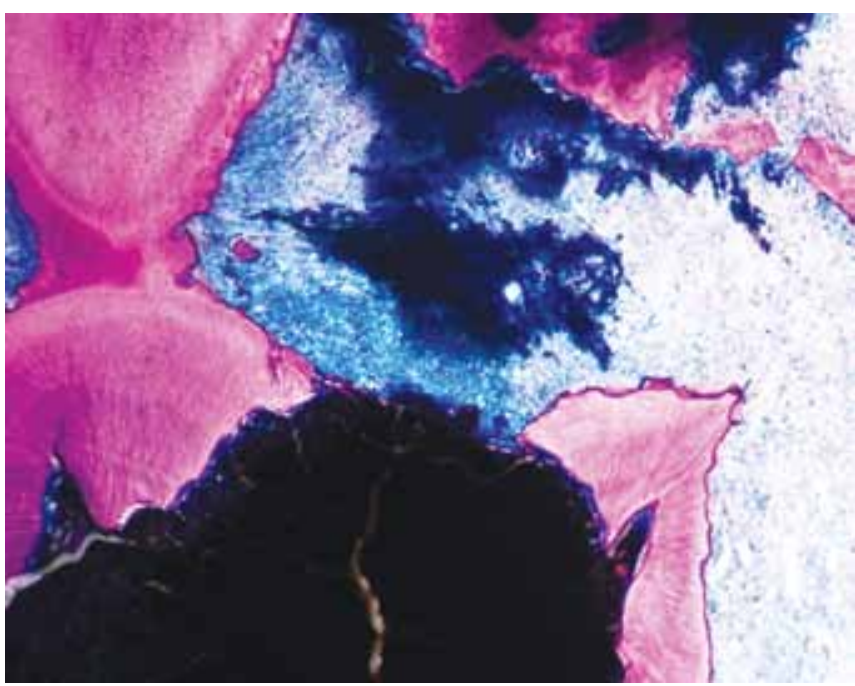

Fig. 1: MM-MTA at 2 weeks: there is a partial irregular hard dentin bridge formation with communication between the dental pulp and the capping material $(\mathrm{H} \& \mathrm{E} \times 40)$

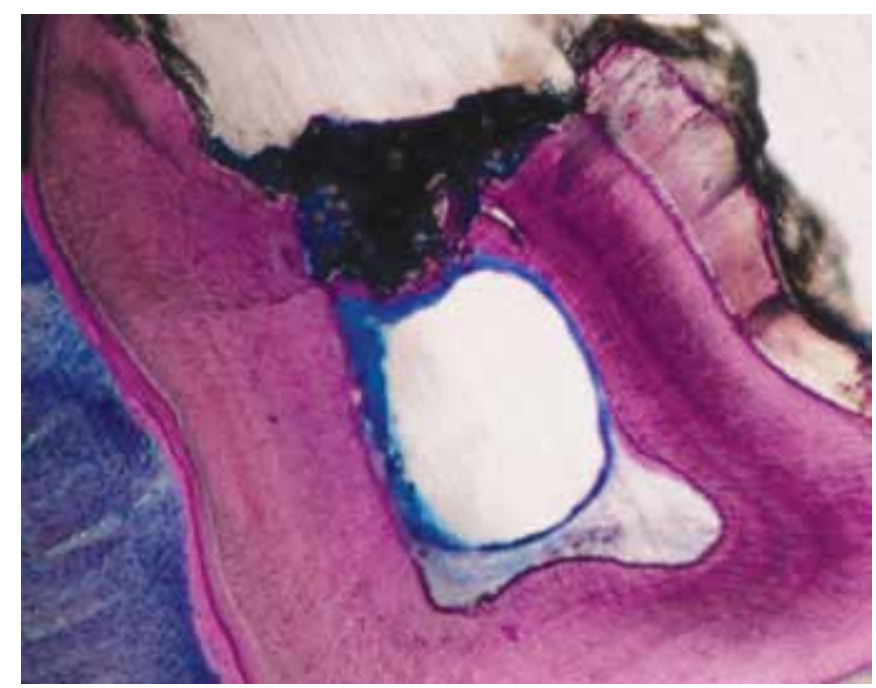

Fig. 2: MM-MTA at 4 weeks: there is an irregular and thin hard tissue bridge with no communication between capping material and dental pulp (H \& E × 40)

Table 1: Number of animals sacrificed in each period postoperatively

\begin{tabular}{|c|c|c|}
\hline 1 week postoperatively & 4 rats sacrificed & $\begin{array}{l}\text { - } 4 \text { molars capped with MM-MTA } \\
\text { - } 4 \text { molars capped with ProRoot MTA }\end{array}$ \\
\hline 2 weeks postoperatively & 4 rats sacrificed & $\begin{array}{l}\text { - } 4 \text { molars capped with MM-MTA } \\
\text { - } 4 \text { molars capped with ProRoot MTA }\end{array}$ \\
\hline 4 weeks postoperatively & 11 rats sacrificed & $\begin{array}{l}\text { - } 9 \text { molars capped with MM-MTA } \\
\text { - } 9 \text { molars capped with ProRoot MTA } \\
\text { - } 4 \text { molars (negative control group) }\end{array}$ \\
\hline
\end{tabular}

\begin{tabular}{lllll}
\multicolumn{5}{c}{ Table 2: Number and percentage N(\%) of teeth treated with MM-MTA that present complete or } \\
partial dentin bridge formation postoperatively & T weeks & 4 weeks & Total \\
\hline MM-MTA & 1 week & 2 weeks & 8 & 4 \\
\hline Presence of dentin bridge (Complete) & $0(0 \%)$ & $0(0 \%)$ & $8(88.9 \%)$ & 5 \\
Presence of dentin bridge (Partial) & $0(0 \%)$ & $3(75 \%)$ & $1(11.1 \%)$ & 4 \\
Absence of dentin bridge & $4(100 \%)$ & $1(25 \%)$ & $0(0 \%)$ & 5 \\
\hline Total & 4 & 4 & 9 & 17 teeth \\
\hline
\end{tabular}

Table 3: Number and percentage $\mathrm{N}(\%)$ of teeth treated with ProRoot MTA that present complete or partial dentin bridge formation

\begin{tabular}{|c|c|c|c|c|}
\hline ProRoot MTA & 1 week & 2 weeks & 4 weeks & Total \\
\hline Complete dentin bridge & $0(0 \%)$ & $0(0 \%)$ & $7(77.8 \%)$ & 7 \\
\hline Partial dentin bridge & $0(0 \%)$ & $4(100 \%)$ & $2(22.2 \%)$ & 6 \\
\hline Absence of dentin bridge & $4(100 \%)$ & $0(0 \%)$ & $0(0 \%)$ & 4 \\
\hline Total & 4 & 4 & 9 & 17 teeth \\
\hline
\end{tabular}

the present study capped with ProRoot MTA or MM-MTA achieved pulp healing in the chronological monitoring of the healing process. In spite of the differences in composition between ProRoot MTA and MM-MTA, this seems to have no effect on their performance in terms of pulp healing, as the result of this study were similar to those of earlier investigations with other animal models after capping with ProRoot MTA. ${ }^{4,6,9,11-15}$

Although the exact mechanism by which MTA induces hard tissue bridge formation is not understood completely, the indications show that the initiation of reparative dentinogenesis of MTA and $\mathrm{Ca}(\mathrm{OH})_{2}$ cement are similar. ${ }^{6}$ Min et $\mathrm{al}^{16}$ evaluated the cellular effects of Portland cement (PC), the basic component of the MTA on cultured human pulp cells and compared PC with other materials including calcium hydroxide cement. They concluded that PC is biocompatible and allows the expression of mineralization-related genes on cultured human pulp cells, which are responsible for inductive process on hard tissue bridge formation with MTA cement. In an other study, Holland et $\mathrm{al}^{17}$ when analyzing the action of MTA after implantation of dentin tubes filled with MTA or calcium hydroxide and distilled water paste in the subcutaneous connective tissue of rats, found large and birefringent granulation deposits near the tube opening and inside the dentinal tubules. These granulations are calcite crystals 


\begin{tabular}{|c|c|c|c|c|}
\hline & MM-MTA & $\begin{array}{l}\text { ProRoot } \\
\text { MTA }\end{array}$ & Control & Total \\
\hline $\begin{array}{l}\text { Complete } \\
\text { dentin bridge }\end{array}$ & $8(88.9 \%)$ & $7(77.8 \%)$ & $0(0 \%)$ & 15 \\
\hline $\begin{array}{l}\text { Partial dentin } \\
\text { bridge }\end{array}$ & $1(11.1 \%)$ & $2(22.2 \%)$ & $0(0 \%)$ & 3 \\
\hline $\begin{array}{l}\text { Absence of } \\
\text { dentin bridge }\end{array}$ & $0(0 \%)$ & $0(0 \%)$ & $4(100 \%)$ & 4 \\
\hline Total & 9 & 9 & 4 & 21 teeth \\
\hline
\end{tabular}

originated from the reaction of calcium hydroxide with tissue carbon dioxide, which allied to fibronectin, are the precursors of mineralized tissue barrier. According to the author, the similar results found for calcium hydroxide and MTA, which does not have calcium hydroxide in its composition, occur because MTA contains calcium oxide, which reacts with tissue fluids to form calcium hydroxide. The release of calcium hydroxide from the hydrating cement is responsible for the alkaline $\mathrm{pH}$ of MTA $(\mathrm{pH}=10.2$, increasing to 12.5 after 3 hours and then remaining constant) and thus for its antibacterial activity. ${ }^{18}$ Also, the completion of the pulp capping in a very short time and adaptation of a clean procedure limited the duration of the pulp exposure to the oral cavity and thus bacterial contamination. Moreover, the use of light-cured composite bonded avoided bacterial leakage post-restoration. ${ }^{19}$

Several species of animals have been used for pulp capping studies including the monkey, ${ }^{5}$ dog, ${ }^{4}$ ferret,${ }^{20}$ mouse, ${ }^{14}$ and rat. ${ }^{21}$ A pulp-capping protocol has been described in the rat model, using the mesial surface of the maxillary first molar, after gingivectomy ${ }^{21}$ or on the occlusal surface. ${ }^{22}$ Using the rat as experimental model in this study offers a number of advantages: it: presents morphological similarities between its molars and its human counterparts, permits the use of adequate numbers of sample for data collection thus facilitates reproducibility. However, small size of the animal complicates surgical procedures during pulp capping as traditional instrumentation is not suitable for use on such teeth. Another limitation of the model presented is that it currently uses healthy teeth, whilst in the clinical situation pulp inflammation is generally present. However, future experiments could simulate caries-like situations by incorporating bacterial infection models using whole live bacteria or bacterial components.

\section{CONCLUSION}

MM-MTA and ProRoot MTA show comparative results in dentin bridge formation after direct pulp capping on rats molars. Further investigations are recommended to analyze pulp healing reaction of MM-MTA on human teeth.

\section{REFERENCES}

1. Accorinte MLR, Loguercio AD, Reis A, Holland R. American Association of Endodontics. an annotated glossary of terms in Endodontics. J Endod 1981;7:G18.

2. Torabinejad M, Chivian N. Clinical applications of mineral trioxide aggregate. Journal of Endodontics 1999;25:197-205.

3. Torabinejad M, Hong CU, McDonald F, Pitt Ford TR. Physical and chemical properties of a new root-end filling material. J Endod 1995a;21:349-353.

4. Parirokh M, Asgary S, Eghbal MJ. A comparative study of white and grey mineral trioxide aggregate as pulp capping agents in dog's teeth. Dental Traumatology 2005;21:150-154.

5. Pitt Ford TR, Torabinejad M, Abedi HR, Bakland LK, Kariyawasam SP. Using mineral trioxide aggregate as a pulpcapping material. J Am Dent Assoc 1996;127:1491-1494.

6. Faraco Junior IM, Holland R. Response of the pulp of dogs to capping with mineral trioxide aggregate or calcium hydroxide cement. Dent Traumatol 2001;17:163-166.

7. Islam I, Chng HK, Yap AU. Comparison of the physical and mechanical properties of MTA and Portland cement. Journal of Endodontics 2006;32:193-197.

8. Camilleri J. Modification of mineral trioxide aggregate: physical and mechanical properties. International Endodontic Journal 2008b;41:843-849.

9. Asgary S, Eghbal MJ, Parirokh M. A comparative study of histologic response to different pulp capping materials and a novel endodontic cement. Oral Surg Oral Med Oral Pathol Oral Radiol Endod 2008;106:609-614.

10. Oliveira IR, Pandolfelli VC, Jacobovitz M. Chemical and mechanical properties of a novel calcium aluminate endodontic cement. International Endodontic Journal 2010;43:1069-1076.

11. Holland R, de Souza V, Murata SS, Nery MJ, Bernabé PFE, Otoboni- Filho JA, Dezan JR E. Healing process of dog dental pulp after pulpotomy and pulp covering with mineral trioxide aggregate or Portland cement. Braz Dent J 2001;12:109-113.

12. Dominguez MS, Whiterspoon DE, Gutmann JL, Opperman LA. Histological and scanning electron microscopy assessment of various vital pulp-therapy materials. Journal of Endodontics 2003;29:324-333.

13. Asgary S, Parirokh M, Eghbal MJ, Ghoddusi J, Eskandarizadeh A. SEM evaluation of neodentinal bridging after direct pulp protection with mineral trioxide aggregate. Aust Endod J 2006;32:26-30.

14. Simon S, Cooper P, Smith A, Picard B, Naulin Ifi C, Berdal A. Evaluation of a new laboratory model for pulp healing: preliminary study. Int Endod J 2008;41:781-790.

15. Tziafas D, Pantelidou O, Alvanou A, Belibasakis G, Papadimitriou $\mathrm{S}$. The dentinogenic effect of mineral trioxide aggregate in shortterm capping experiments. Int Endod J 2002;35:245-254.

16. Min KS, Chang HS, Bae JM, Park SH, Hong CU, Kim EC. Human pulp cells response to Portland cement in vitro. Journal of Endodontics 2007;33:163-166.

17. Holland R, de Souza V, Nery MJ, Faraco Júnior IM, Bernabé PF, Otoboni-Filho JA, Dezan Júnior E. Reaction of rat connective tissue to implanted dentin tube filled with mineral trioxide aggregate, Portland cement or calcium hydroxide. Braz Dent J 2001;12:3-8.

18. Camilleri J. Hydration mechanisms of mineral trioxide aggregate. International Endodontic Journal 2007;40:462-470. 
19. Pradelle-Plasse NC, Besnault C, Souad N, Colon P. Influence of new light curing units and bonding agents on the microleakage of class $\mathrm{V}$ composite resin restorations. American Journal of Dentistry 2003;16:409-413.

20. Smith AJ, Tobias RS, Murray PE. Transdentinal stimulation of reactionary dentinigenesis in ferrets by dentine matrix components. Journal of Dentistry 2001;29:341-346.

21. Decup F, Six N, Palmier B. Bone sialoprotein-induced reparative dentinogenesis in the pulp of rat's molar. Clinical Oral Investigation 2000;4:110-119.

22. Lovschall H, Tummers M, Thesleff I, Fütchbauer EM, Poulsen. Activation of the Notch signaling pathway in response to pulp capping of rat molars. K European Journal of Oral Science 2005;113:312-317.

\section{ABOUT THE AUTHORS}

Issam Tanios Khalil (Corresponding Author)

Assistant Professor, Department of Endodontics, Saint Joseph University, Lebanon, e-mail: isamklil@cyberia.net.lb

\section{Tony Sarkis}

Private Practice, Department of Endodontics, Lebanon

\section{Alfred Naaman}

Chairman, Department of Endodontics, Saint Joseph University Lebanon 